\title{
Research and application of bypass replacement logic and risk control of stability control device
}

\author{
WANG Gang ${ }^{1 *}$, XU Ke ${ }^{2}$ \\ ${ }^{1}$ Guangxi Power Grid Dispatching Control Center, Nanning, Guangxi, 530023, China \\ ${ }^{2}$ NARI-Relays Electric Co., Ltd., Nanjing, Jiangsu, 211102, China
}

\begin{abstract}
In order to prevent the power failure of the whole line caused by the maintenance of line switch, bypass switch is set in $220 \mathrm{kV}$ Main Wiring of some power plants. When the bypass replaces a line, there are three states in turn: line, bypass and line parallel operation, bypass operation. The bypass replacement logic of stability control device needs to correctly distinguish and switch these three states. This paper deeply studies the variation law of bypass, line analog and switching value in the whole bypass replacement process, puts forward the correct switching judgment method of line outage, trip and overload criteria, as well as the operation risk and prevention and control measures of bypass platen in the bypass replacement process, and then takes a power plant stability control device as an example to verify the results, which shows that the bypass replacement logic proposed in this paper is feasible. Risk prevention and control measures can ensure the correctness of logical discrimination of stability control devices in the process of bypass replacement, and can be extended to other power plant stability control devices.
\end{abstract}

\section{Introduction}

There are few outgoing lines in some power plants or substations in China. In order to ensure that the whole line does not need to be cut off when a line switch is cut off for maintenance, the bypass switch interval is increased. When a line switch is cut off for maintenance, the bypass switch is replaced by the line switch, and the whole line can continue to transmit power normally.

In order to solve the problem of safety and stability of power plant, some power plants are equipped with stability control devices, which form a stability control system with other substation stability control devices. In case of unit instability, line overload and other problems after failure, measures such as cutting machine, pressure reduction output are taken. In order to achieve the above functions, the stability control device needs to be connected with the analog quantities such as three-phase current and voltage of primary equipment such as relevant lines and bypass, and the switching quantities such as switch position signal, and then carry out the logic discrimination of shutdown, trip and overload of each primary equipment. In the process of line bypass, in order to ensure the stability control device to make accurate logical discrimination, it is necessary to use the correct line and bypass switch information, and specify the operation sequence of each bypass platen to prevent the operation risk.

This paper deeply analyzes and studies the variation law of bypass, line analog and switching value in the whole line bypass switching operation process, puts forward the judgment method of line outage, trip and overload logic correct switching in each operation state, and puts forward the bypass risk identification and prevention and control measures, and then takes a hydropower plant stability control device as an example to verify.

\section{The process of line substitution}

Suppose that the high voltage side of a power plant or substation adopts the single bus section with bypass connection mode, there are two $220 \mathrm{kV}$ lines and one bypass in total. The wiring diagram under normal mode is shown in Figure 1.

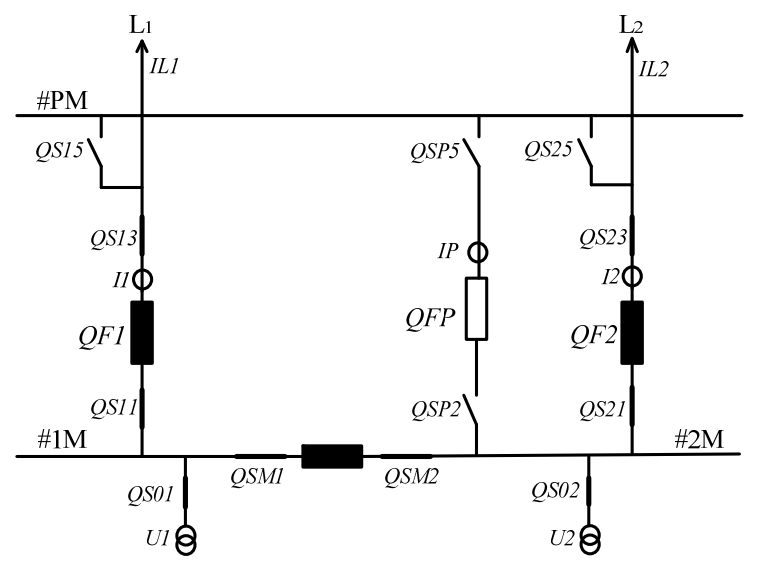

Figure 1. Wiring diagram of 220kV Substation under normal mode

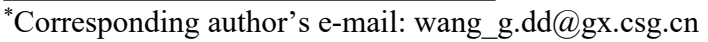


In the figure above, the bus voltages of $\# 1 \mathrm{M}$ and $\# 2 \mathrm{M}$ are $\mathrm{U} 1$ and $\mathrm{U} 2$ respectively, the lines $\mathrm{L} 1$ and $\mathrm{L} 2$ are fixed to \#1M and \#2M respectively, the switches QF1 and QF2 are closed, the current flowing through the lines is IL1 and IL2 respectively, the current flowing through the line switches is I1 and I2 respectively, and the bypass is connected between \#2M and \#PM.

Under normal mode, the stability control device uses analog quantities such as I1 of line L1 switch and U1 of \#1M switch, as well as QF1 switch position to judge line L1 shutdown and trip, and uses analog quantity to judge overload.

Assuming that the maintenance of line L1 switch needs to be replaced, the operator on duty of the power plant first switches on qsp2 and qsp5, and then switches on QFP to charge PM, confirming that PM operates normally without load. At this time, qs15 of line L1 has not been closed, so line L1 still uses the line switch current I1. Now disconnect QFP, put in the L1 pressure plate of the bypass line of the stability control device, and then close qs15, and then close QFP. Line L1 switch and bypass switch operate in parallel, and the current of line $\mathrm{L} 1$ becomes IL1 = I1 + IP.

In this operation state, the stability control device must use the "sum current" of line L1 switch and bypass switch to replace the original line L1 switch current, and switches QF1 and QFP must be disconnected at the same time to judge line L1 shutdown and trip.

The wiring diagram of parallel operation of bypass and substituted line switch is shown in Figure 2.

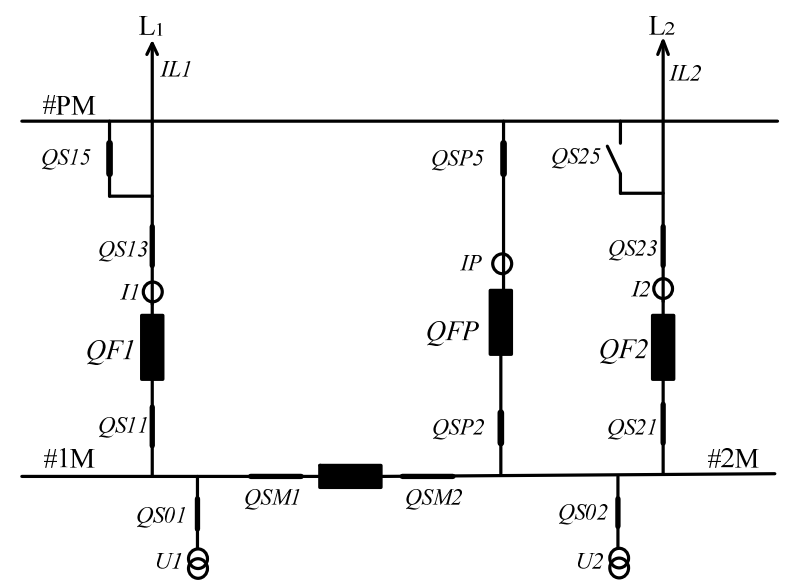

Figure 2. Wiring diagram for parallel operation of bypass and substituted line switches

After the bypass and line L1 switch operate in parallel, the operator on duty of the power plant continues to operate and disconnect $\mathrm{QF} 1$, and the current of line L1 becomes IL1 = IP. In order to prevent misjudgment of stability control device caused by test current, voltage and on-off switch when line L1 switch is powered off for maintenance test after bypass replacement, the stability control device must automatically switch to only use bypass switch current IP when line L1 switch current I1 is less than the set no current setting value, and the position signal must also switch to bypass switch QFP position.

The wiring diagram after bypass replacement is shown in Figure 3.

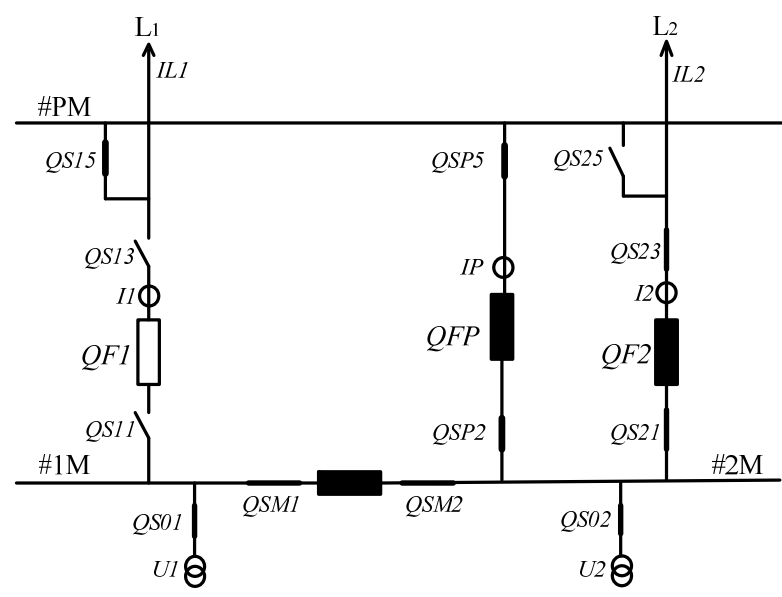

Figure 3. Wiring diagram after completion of bypass

After the power-off maintenance of line L1 switch is completed, the bypass recovery process is the reverse process of the above bypass process. Exit the bypass of the stability control device to replace the line L1 pressing plate, and then carry out the bypass recovery operation. The device can also switch the current, voltage and position correctly according to the above process. The recovery process of single bus section with bypass connection

\section{Process processing logic of stability control device}

Under the normal operation mode, the device uses the voltage, current and position signals of the line switch to judge the overload, start stop and trip of the line. When the side-by-side pressing plate of the line is put into operation, and then the bypass switch is closed. When the bypass switch current IP is greater than the no current setting value, the device uses two switches "and current", and the position takes the "or" of the two switches, so that the single switch position jumps After the line switch is disconnected, switch to the bypass switch, and the device uses the current, voltage and closing position of the bypass switch.

At the end of the work, carry out the bypass recovery. First exit the bypass pressing plate of the line, and then close the line switch. When the line switch current I1 is greater than the no current setting value, the bypass switch and the line switch operate in parallel. The device uses two switches "and current", and the position is taken as two on-off "or"; after the bypass switch is disconnected, switch to the line switch, and the device is started Return to the normal mode, use the voltage, current and position signal of the line switch, and the whole bypass process ends.

The processing logic of the next replacement process of the stability control device is shown in Figure 4. 


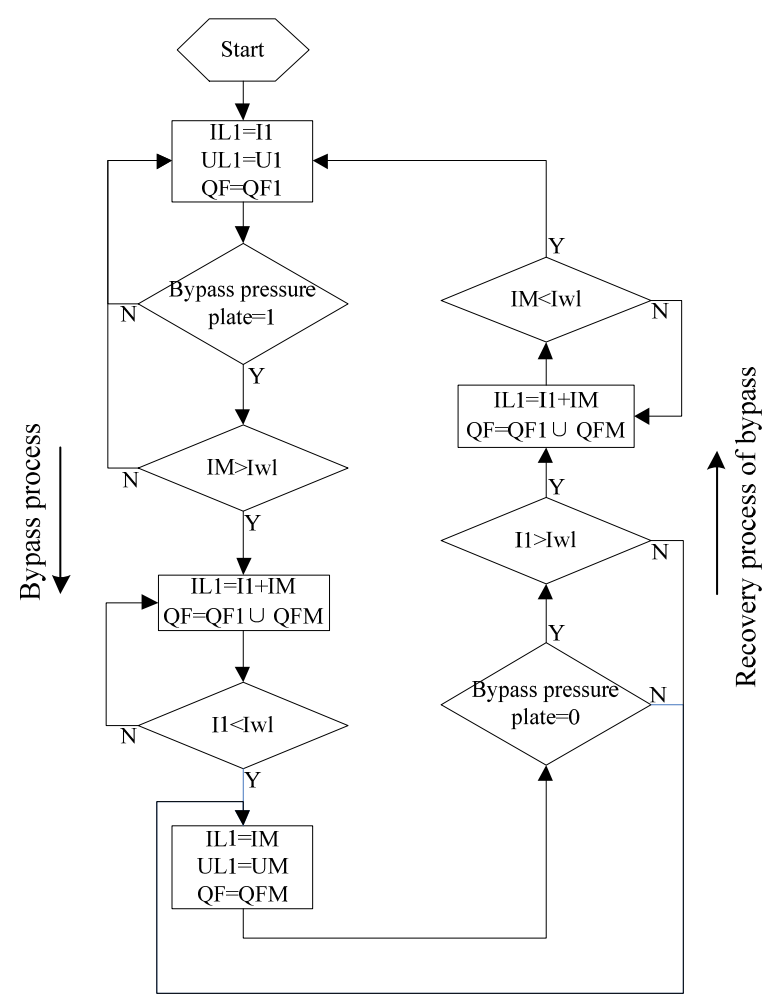

Figure 4. Processing logic of the side process of the stability control device

In the figure above, IWL is the current free setting value of the line and bypass switch, which is used to determine whether the switch is on or off. The current "+" sign indicates that the current of two switches is added, and the closing " $\cup$ " sign indicates that the closing of two switches is "or".

\section{Risk identification and control of stability control device}

As can be seen from the previous bypass process, there are two major risks in the whole bypass and bypass recovery process. One is that the incorrect operation sequence of the bypass platen leads to the misjudgment of current and closing position, and the other is that the current of the line and bypass switch is too small to switch smoothly.

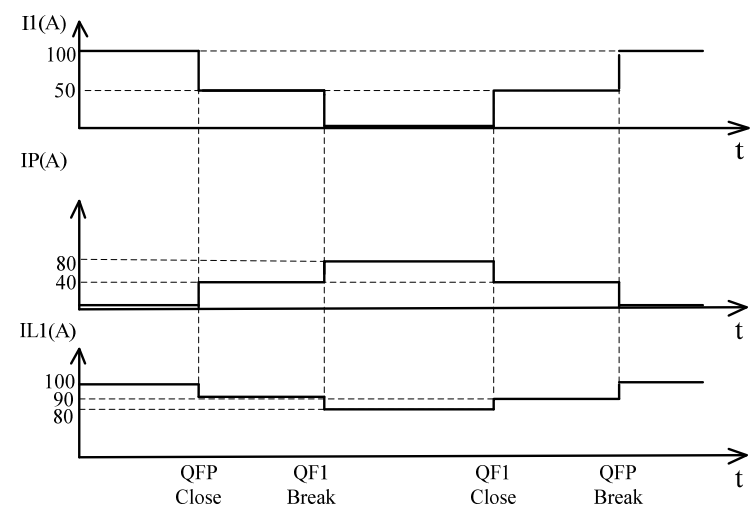

Figure 5. Current and switch closing change sequence diagram of stability control device

\section{1 risk and operation sequence requirements of the on / off of the bypass platen}

If the bypass switch QFP is closed and the bypass switch is not put into operation, the device will still use the original line current and closing position after the line and bypass switch are running in parallel, resulting in the misoperation or refusal of the stability control strategy. Therefore, the bypass switch QFP must be put into operation before the bypass switch QFP is closed.

The recovery process of the bypass switch is similar. After the work is finished, it is necessary to exit the bypass switch in advance. Otherwise, after the line switch is closed and the line switch and the bypass switch operate in parallel, the device still uses the bypass switch current and closing position, resulting in the misoperation or refusal of the stability control strategy.

\section{2 risk and prevention and control measures of line current too small to switch}

When the bypass switch QFP is closed, if the power flow of the line is light and the bypass switch current is less than the current free setting IWL, the current and closing cannot be switched

(1) The device can set the zero current setting IWL as small as possible within the range of accuracy.

(2) Select the time operation when the line current is greater than $2 \sim 3$ times the current free setting IWL.

(3) Switch position switching is used instead of current switching.

\section{Analysis of the operation example of the stability control device in a hydropower plant}

In March 2021, the stability control device of a power plant was replaced when it was due. The original device bypass replacement logic only considered the current switching, and the replaced device bypass replacement logic added the switching logic of "or" for closing position. After the replacement of the stability control device, the tester and switch simulator were used for the bypass test. The time sequence diagram of the current and closing change of the stability control device during the test is shown in Figure 5.

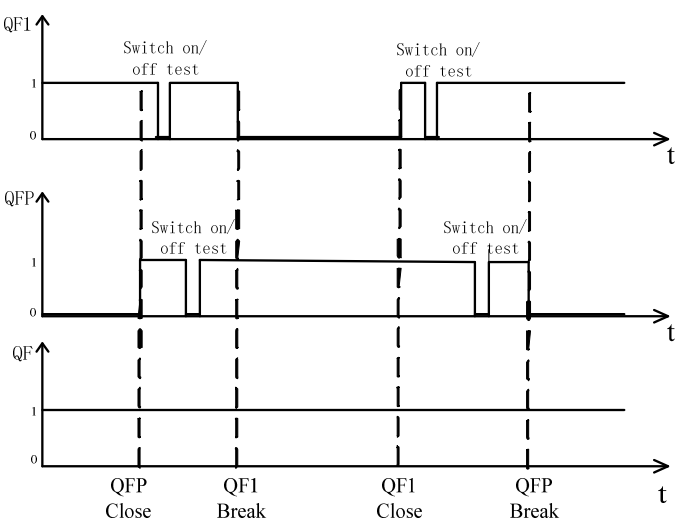


It can be seen from the above figure that the device can correctly judge the current value and switch closing position in the process of bypass replacement and bypass replacement recovery; in the process of parallel operation of line and bypass switch, the opening and closing of line or bypass switch will not cause the device to misjudge shutdown and trip. When the power plant operators on duty select the line with large power flow, operate the side pressure plate in strict accordance with the operation sequence requirements, the device can correctly identify the shutdown and trip, and will not cause the misoperation or refusal of the stability control strategy.

\section{Conclusion}

In this paper, the voltage, current and closing change laws of bypass and substituted lines in the whole bypass replacement process are deeply studied, and the correct switching judgment method of line outage, tripping and overload criteria is proposed, as well as the risk and prevention measures of the bypass platen operation and line current too small in the bypass replacement process. Then, the bypass operation of a power plant stability control device is taken as an example to verify the results. It shows that the bypass replacement logic and risk prevention and control measures proposed in this paper can ensure the correctness of the logic discrimination of the stability control device in the bypass process, and can be extended to various bypass replacement logic of the stability control device in other power plants.

\section{Acknowledgments}

Here, I would like to express my heartfelt thanks to the leaders and colleagues of the unit, as well as the stability control device manufacturers and power plant personnel for their strong support in the logic transformation of the bypass replacement of the stability control device in the hydropower plant.

\section{References}

1. He yangzan, Wen Zengyin. Power system analysis (Volume 2) [M]. Wuhan: Huazhong University of science and Technology Press, 2002:52-54

2. Ying Bin; Tang Yiqin. Discussion on some special problems of stability control device [J]. Electric power automation equipment, 2006,26 (3): 93-94

3. Yang Ruixiong. Risk analysis and Discussion on risk control measures of substation bypass [J]. Electrical technology, 2016,11 (a): 49-51

4. Zheng maoran et al. Risk analysis and prevention and control measures of $220 \mathrm{kV}$ bypass substitution in China Southern Power Grid [J]. China Southern Power Grid technology, 2014,8 (1): 56-59

5. Liu Yang. An improved bypass replacement automatic identification strategy [J]. Dazhong science and technology, 2009, 124 (12), 57-58
6. NARI Relay. Project specification for stability control system of Guangxi 220kV Dahua Power Plant (r1.00) [M]. Nanjing: Nari Jibao Electric Co., Ltd 